\title{
A MEMÓRIA AFRO DIASPÓRICA FEMININA COMO METODOLOGIA PARA PESQUISA EM EDUCAÇÃO
}

\author{
AFRO DIASPORIC FEMALE MEMORY AS A METHODOLOGY FOR RESEARCH IN \\ EDUCATION
}

\author{
MEMORIA FEMENINA AFRODASPÓRICA COMO METODOLOGÍA PARA LA \\ INVESTIGACIÓN EN EDUCACIÓN
}

Cecilia Conceição Moreira Soares

Universidade do Estado da Bahia - Brasil

Grácia Lorena da Silva Jorge

Universidade Estadual do Sudoeste da Bahia - Brasil

\begin{abstract}
Resumo: $\mathrm{O}$ artigo apresentado pretende, de forma preliminar, discutir a importância do uso da memória feminina diaspórica e das narrativas em entrevistas sobre as vivências de mulheres negras, enquanto fonte privilegiada para intepretação das nuances de suas vidas relacionadas aos processos de educação. As lembranças, a partir das narrativas de mulheres negras sobre determinados contextos do passado escravista até os dias atuais, constituem uma prática libertadora ao se posicionarem durante os registros dolorosos sobre a família e o cotidiano, marcado pela opressão e exclusão social. Quanto mais melanina suas peles refletem, mais forte e incisiva é a rejeição de suas existências, provavelmente por seus corpos negros retintos estarem associados historicamente à ancestralidade africana. Embora sejam inúmeras as possibilidades de análise para a pesquisa em Educação, com o uso da oralidade e memória escrita, sugerimos alguns caminhos metodológicos para arguição das informações. Como por exemplo, a pesquisa qualitativa compreensiva proposta por Crusoé (2014) e Amado; Crusoé (2017), com base na análise de conteúdo de Bardin (2011; 1977). Para escrita deste trabalho utilizamos alguns teóricos que serão apresentados ao longo do texto, tais como: Le Goff (1994); Nora (1993); Pollak (1989); Evaristo (2016; 2007), Moreira (2007); Fonseca e Souza (2006); Jesus (2000); Geertz (1978); Barreto (2018); Candau (2019); Streck (2006); Delgado (2007); Bosi (1994); Clark (2019); Figueiredo (2009); Soares (2006); Maldonado-Torres (2018).
\end{abstract}

Palavras chave: Educação; Memória feminina diaspórica; Metodologia da pesquisa.

\begin{abstract}
The article presented intends, in a preliminary way, to discuss the importance of using diaporic female memory and narratives in interviews about the experiences of black women, as a privileged source for interpreting the nuances of their lives related to education processes. The memories, based on the narratives of black women about certain contexts from the slavery past to the present day, constitute a liberating practice as they position themselves during the painful records about the family and daily life, marked by oppression and social exclusion. The more melanin their skin reflects, the stronger and more incisive is the rejection of their existence, probably because their dark black bodies are historically associated with African ancestry. Although there are countless possibilities of analysis for research in Education, with the use of orality and written memory, we suggest some methodological ways to argue the information. For example, the comprehensive qualitative research proposed by Crusoé (2014) and Amado; Crusoé (2017), based on Bardin's (2011; 1977) content analysis.
\end{abstract}


To write this work we use some theorists that will be presented throughout the text, such as: Le Goff (1994); Nora (1993); Pollak (1989); Evaristo (2016; 2007), Moreira (2007); Fonseca and Souza (2006); Jesus (2000); Geertz (1978); Barreto (2018); Canada (2019); Streck (2006); Delgado (2007); Bosi (1994); Clark (2019); Figueiredo (2009); Soares (2006); Maldonado-Torres (2018).

Keywords: Education; Diaspora female memory; Research methodology.

Resumen: El artículo presentado pretende, de manera preliminar, discutir la importancia de utilizar la memoria y narrativas femeninas diapóricas en entrevistas sobre las vivencias de las mujeres negras, como una fuente privilegiada para interpretar los matices de sus vidas relacionados con los procesos educativos. Los recuerdos, basados en las narrativas de mujeres negras sobre ciertos contextos desde el pasado esclavista hasta la actualidad, constituyen una práctica liberadora al posicionarse durante los dolorosos registros sobre la vida familiar y cotidiana, marcados por la opresión y la exclusión social. Cuanto más melanina refleja su piel, más fuerte e incisivo es el rechazo de su existencia, probablemente porque sus cuerpos negros oscuros están históricamente asociados con la ascendencia africana. Si bien existen innumerables posibilidades de análisis para la investigación en Educación, con el uso de la oralidad y la memoria escrita, sugerimos algunas formas metodológicas de argumentar la información. Por ejemplo, la investigación cualitativa integral propuesta por Crusoé (2014) y Amado; Crusoé (2017), basado en el análisis de contenido de Bardin $(2011 ; 1977)$. Para escribir este trabajo utilizamos algunos teóricos que se presentarán a lo largo del texto, como: Le Goff (1994); Nora (1993); Pollak (1989); Evaristo (2016; 2007), Moreira (2007); Fonseca y Souza (2006); Jesús (2000); Geertz (1978); Barreto (2018); Canadá (2019); Streck (2006); Delgado (2007); Bosi (1994); Clark (2019); Figueiredo (2009); Soares (2006); Maldonado-Torres (2018).

Palabras clave: Educación; Memoria femenina de la diáspora; Metodología de investigación.

\section{Introdução}

De acordo com Le Goff (1994), a memória destaca-se pela capacidade de conservar certas informações, remete-nos em primeiro lugar a um conjunto de funções psíquicas, graças às quais homens e mulheres podem atualizar impressões ou informações passadas, ou que eles(as) representam como passadas. As informações ou impressões sobre o passado é elemento essencial à constituição do que se costuma chamar de identidade, individual ou coletiva, cuja busca é uma das atividades fundamentais dos indivíduos e das sociedades de hoje. (LE GOFF, 1994, p. 432)

A memória é um fenômeno sempre atual, mas em consonância com o passado ou representação do passado. Para Nora (1993) é afetiva e mágica, a memória não se acomoda a detalhes que a confortam: "ela se alimenta de lembranças vagas, telescópicas, globais ou flutuantes, particulares ou simbólicas, sensível a todas as transferências, cenas, censuras ou projeções." As lembranças, por vezes vagas, "constituem um dos meios para se alcançar a memória social e abordar os problemas do tempo e da história, relativamente aos quais a memória está, ora em retraimento, ora em transbordamento”. (Le Goff, 1990, p.368). 
Dessa forma, compreende-se que memória está aberta à "dialética da lembrança e do esquecimento, inconsciente de suas deformações sucessivas, vulnerável a todos os usos e manipulações, suscetível a longas latências e repentinas revitalizações." (NORA, 1993, p. 9).

Michael Pollak (1989) nos assevera sobre a importância dos ditos e dos não-ditos para a construção de uma memória, seja ela coletiva ou individual. $\mathrm{O}$ ato de lembrar implica uma ação coletiva dos acontecimentos e das interpretações do passado que se deseja conservar "... se integra, como vimos, em tentativas mais ou menos conscientes de definir e de reforçar sentimentos de pertencimento e fronteiras sociais entre coletividades de tamanhos diferentes: partidos, sindicatos, igrejas, aldeias, regiões, clãs, famílias, nações etc.” (POLLAK, 1989, p. 7).

Nesse sentido, lembrar precede a seleção de imagens e narrativas que estabeleçam a ponte com o passado, cujo fator tempo provoca alterações e/ou mesmo ajustes na seleção dos fatos que na subjetividade, faz emergir outras lembranças e as implicações do que foi lembrado ou restaurado num processo complexo de seleção-ação-narrativa do evento.

As lembranças, a partir das narrativas de mulheres negras sobre determinados contextos do passado escravista até os dias atuais, constituem uma prática libertadora ao se posicionarem durante os registros dolorosos sobre a família e o cotidiano, marcado pela opressão e exclusão social. Quanto mais melanina suas peles refletem, mais forte e incisiva é a rejeição de suas existências, provavelmente por seus corpos negros retintos estarem associados historicamente à ancestralidade africana. $\mathrm{O}$ exercício de lembrar e relembrar tem função política e pedagógica, remontar o passado através dos fragmentos da memória é uma ação importante para provocar a busca pelo conhecimento/reconhecimento das experiências femininas negras vivenciadas por uma coletividade, em diferentes espaços sociais. Exemplo dessa postura política ao narrar fatos relacionados à vivência da família negra, podemos citar Evaristo:

Mas eu nunca esquecera a minha mãe. Reconhecia a importância dela na minha vida, não só dela, mas de minhas tias e de todas as mulheres de minha família. E também, já naquela época, eu entoava cantos de louvor a todas nossas ancestrais, que desde a África vinham arando a terra da vida com as suas próprias mãos, palavras e sangue. Não, eu não esqueço essas Senhoras, nossas Yabás, donas de tantas sabedorias. Mas de que cor eram os olhos de minha mãe? (EVARISTO, 2016, p. 18).

Diante dessa descrição do conto Olhos D'água (2016), embora não seja identificada a personagem, acreditamos que essa história seja paradigmática para muitas famílias negras perpassadas pela violência da escravidão, resultando no esfacelamento da família negra. No conto, as memórias são entrelaçadas, reavivando questões importantes relacionadas aos problemas vivenciados não só pela protagonista como também por outras mulheres negras e 
famílias negras no país. Através do ato de recordar, a narradora recupera imagens da infância que a conectam a sua origem e à figura da matriarca. Os olhos da mãe, sempre marejados, refletem as dores e angústias que marcam as suas experiências de mulher negra e de poucos recursos, contudo, também podem representar a força e capacidade de não sucumbir diante dos infortúnios da vida. Nesse contexto, as lembranças da protagonista e as recordações de sua mãe se misturam e se encontram, numa fusão entre passado e presente:

[...] Às vezes, as histórias da infância de minha mãe confundiam-se com as de minha própria infância. Lembro-me de que muitas vezes, quando a mãe cozinhava, da panela subia cheiro algum. Era como se cozinhasse, ali, apenas o nosso desesperado desejo de alimento. (EVARISTO, 2015, p. 16)

Aludimos que o processo de recomposição das histórias pela memória coletiva é instrumento fundamental para a escrita de histórias de vida das mulheres negras, em diferentes temas sociais como religião, economia, trabalho, arte, literatura e, principalmente educação, todas negligenciadas pela escrita oficial e ocidentalizante. De acordo com Moreira (2007, p.75) "a luta das mulheres negras é comprometida com o resgate das suas histórias, recriando em suas potencialidades a tentativa de buscar mudanças que permitam novas experiências relacionais de poder na sociedade". Ainda que tenhamos alguns estudos específicos acadêmicos e literários, carecemos de análises sistemáticas quantitativamente significativas.

Apesar da importância das narrativas pessoais baseadas na memória coletiva para a obtenção de informações sobre grupos específicos e/ou recorre-se para corroborar dados realizados a partir de outros referenciais, ainda pairam incertezas e dúvidas relativas ao uso da memória como metodologia, ou seja, conjunto de métodos, caminhos para procedimentos analíticos teóricos e metodológicos que, arrolados aos dados, permitam explicar determinada realidade. ${ }^{1}$. Trata-se de questões relacionadas aos procedimentos e análises dos dados gerados após os registros gravados e/ou anotados, e posteriormente transcritos ou oriundos das entrevistas, estruturadas ou não, cujas informações possibilitam a escrita interpretativa entrelaçando as informações. Essas são, em linhas gerais, os principais embates experimentados pelos pesquisadores que privilegiam a memória também como técnica de pesquisa, através de vários instrumentos para análise dos dados na operacionalização da investigação.

De fato, na ausência de maiores informações sobre o passado e determinadas circunstâncias do presente, busca-se nas narrativas de grupos sociais a memória para registro

\footnotetext{
${ }^{1}$ Sobre o uso do método para pesquisa, consultar para SANTOS, Edimilson Menezes. Observações introdutórias ao nexo entre método e conhecimento em Descartes. In: AMADO, João; CRUSOÉ, Nilma Margarida de Castro. Referenciais Teóricos e metodológicos em Educação e Ciências Sociais. Vitória da Conquista: Edições UESB, 2017, pp.21-37. OLIVEIRA, Maria Marly de. Como se faz pesquisa qualitativa. $7{ }^{\text {a }}$ ed. Rio de Janeiro, Editora Vozes, 2016.
} 
de suas experiências individuais e coletivas. Através do método da História Oral ${ }^{2}$, Histórias de Vida $^{3}$, Biografias e Estudos (auto)biográficos ${ }^{4}$, emergem as lembranças daquelas(es) cujas histórias foram violentadas pela escrita homogeneizante e excludente da história, principalmente em espaços que lidaram com regimes opressores, relegando aos indivíduos a invisibilidade em resposta aos eixos interseccionais que os distinguem de outras pessoas, particularmente as mulheres negras.

Para além da proposta metodológica da História, a partir de relatos orais e escritas pessoais, algumas mulheres negras tornaram-se representativas de uma escrita epistêmica diferenciada e crítica, partindo da denúncia do silêncio de suas histórias, narrando-as numa outra projeção de registros, perpassado pela dor da lembrança. Mas, onde recompõem suas trajetórias e experiências, cujas palavras carregadas de emoções e subjetividades nos reportam para os desafios do cotidiano enfrentado por muitas mulheres negras. Ainda que algumas situações não sejam restritas à vida das mulheres negras, é sobre o obscurantismo dado as suas vivências que tratam as produções literárias também chamadas de diaspóricas femininas negras. Os acontecimentos nos relatos pessoais estão relacionados às vivências e estratégias de sobrevivências, esses registros constituem descrições importantes sobre as nuances do dia a dia, e representam testemunhos do passado e da vida das mulheres negras na atualidade.

A submersão em lembranças dolorosas faz vir à tona os acontecimentos ressignificados e, no contraponto, os exemplos de superação, com sentimento de pertencimento identitário fortalecido, postura indissociável da arte de uma escrita potente, por vezes contundente, mas demarcando processos, caminhadas e descobertas. Sobretudo, escrevem sobre suas vivências e essas são múltiplas, porém, as trajetórias de várias mulheres se intercruzam, independente do encontro, são experiências coletivas, mas cujo significado é a superação das imagens sociais distorcidas, desrespeitosas e a exclusão através de vários processos como a educação, a saúde, o trabalho, o lazer, a beleza, a maternidade, dentre outros.

As narrativas de histórias de vidas e autobiografias dos sujeitos representam a singularidade de acontecimentos selecionados em conexão com as estruturais sociais. Os registros femininos afro diapóricos literários e no contexto dos estudos acadêmicos,

\footnotetext{
${ }^{2}$ AMADO: FERREIRA. Janaína; Marieta de Moraes. Usos e abusos da História Oral. Rio de janeiro, Editora Fundação Getúlio Vargas, 1996.

${ }^{3}$ MOREIRA,Núbia Regina. A construção teórico-metodológico das trajetórias de vida na pesquisa sociológica. In: AMADO, João; CRUSOÉ, Nilma Margarida de Castro (Org.). Referenciais Teóricos e metodológicos em Educação e Ciências Sociais. Vitória da Conquista :Edições UESB,2017, pp.167194. pp.61-94.

${ }^{4}$ SOUZA:CRUZ. Elizeu Clementino de; Núbia da Silva. Pesquisa (auto)biográfica: sentidos e implicações para o campo educacional. In: AMADO, João; CRUSOÉ, Nilma Margarida de Castro (Org.). Referenciais Teóricos e metodológicos em Educação e Ciências Sociais. Vitória da Conquista: Edições UESB, 2017, p.167/194.
} 
perpassados pelas questões de etnia/ raça, gênero, classe, por exemplo, evidenciam experiências no cotidiano onde as relações sociais estão imbricadas pelas concepções que subalternizam o ser negro na sua totalidade. Quase nunca os acontecimentos ocorrem dissociados desses itens, e que vem a definir o pertencimento identitário, resultado do processo de busca e reencontro com a ancestralidade afro-brasileira e movimentos políticos sociais negros, dentro e fora da universidade. Até porque, o encontro e/ou redescoberta desse universo independe do vínculo político identitário com os grupos organizados. Está além das prerrogativas de uma organização militante.

Na tese de doutorado Encontros, Desencontros e (Re) Encontros da Identidade de Matriz Africana: A História de Cecilia do Bonocô Onã Sabagi, defendida em 20095 , a autora fez uso dos relatos orais e registros do próprio punho da principal entrevistada para recomposição da memória sobre a constituição litúrgica e edificação material do terreiro de candomblé Ilê Axé Maroketu em Salvador - Bahia. A proposta de história de vida e o lugar social ocupado pela mulher negra, identificada com as práticas religiosas afro-brasileiras, é um exemplo do que se pode construir academicamente a partir da memória feminina negra diaspórica, independente de uma relação militante política em termos partidários. Embora esse viés também seja importante. Nesse trabalho, a questão relacional com o tempo das narrativas é aspecto importante, de acordo com (SOUZA; CRUZ, 2017, p.185):

A questão da temporalidade é uma das características mais marcantes da pesquisa (auto)biográfica, porque se inscreve no movimento narrativo dos acontecimentos, sem, contudo, adotar uma perspectiva diacrônica e uma objetividade discursiva das experiências. Trata-se de contar a sua própria história, levando em consideração, além dos acontecimentos mais significativos, inscritos num tempo, o que exige do narrador modos próprios de narrar acontecimentos da vida e sobre a vida, que revela compreensões do mundo, de si mesmo e aprendizagens experiências construídas ao longo da vida.

$\mathrm{O}$ acolhimento às narrativas sobre a memória ancestral, experiências pessoais e as conjunturas econômicas que violaram o direito à humanidade dos negros e negras, são refletidas em fatos relacionados à infância, adolescência e vida adulta, onde aspectos relacionados ao fenótipo negro africano são alvo de preconceitos, esses traços, ainda que só de longe rememore a relação com os africanos escravizados no Brasil, dão indícios sobre a construção de uma explicação baseada na mentalidade escravista e racista para justificar os destratos e agressões reportados aos descendentes de africanos de modo geral.

\footnotetext{
${ }^{5}$ Soares, Cecilia C. M. Tese defendida em 2009 pela Universidade Federal de Pernambuco, Programa de Antropologia.
} 
A memória deve ser apreendida no seu conjunto e inter-relação com as diferentes sociabilidades. Cabe a inferência sobre em que momento as pessoas são provocadas a lembrar como organizam e narram essa lembrança, selecionam fatos, alteram as imagens. A memória se processa o tempo todo, culminando com novos cenários e redefinindo o papel dos sujeitos. (SOARES, 2009, p. 5)

Reativar, selecionar fatos, realinhá-los, faz parte do processo das lembranças para efeito das narrativas pessoais que, tomadas como método para pesquisa em educação, não deve se opor à análise metodológica e desprender-se da intenção de tornar os fatos relevantes como verdades desprovidas de intencionalidades e subjetividades do sujeito que a constroem. Talvez, aqui, mais um embate no sentido de acolhimentos das narrativas e as relações que estabelecem com o pesquisador e a pertinência da análise da descrição (PASSERON, 1995).

Nesse sentido, lembrar precede a seleção de imagens e próprias narrativas que estabeleçam a ponte com o passado, cujo fator tempo provoca alterações e/ou mesmo ajustes na seleção dos fatos que, na subjetividade, faz emergir outras lembranças e as implicações do que foi lembrado ou restaurado num processo complexo de seleção-ação-narrativa do evento.

Dito isso, a História Oral consiste em uma metodologia de pesquisa onde se realiza entrevistas com pessoas que podem testemunhar sobre acontecimentos, conjunturas, instituições, modos de vida ou outros aspectos da história contemporânea. Embora seja utilizada desde os 1950, particularmente nos Estados Unidos, na Europa e no México, foi introduzida no Brasil na década de 1970. Nesse período, foi criado o Programa de História Oral do CPDOC/FGV - Centro de Pesquisa e Documentação de História Contemporânea do Brasil. Sua difusão em termos de proposta metodológica de pesquisa se expandiu a partir de 1990, quando um movimento de sensibilização a história oral ganhou adeptos. Em 1994, foi criada a Associação Brasileira de História Oral, e dois anos depois, a associação Internacional de História Oral e, desde então, difundiu-se bastante. Conquistou também cada vez mais seguidores, ampliando o intercâmbio entre os que a praticam: historiadores, antropólogos, cientistas políticos, sociólogos, pedagogos, teóricos da literatura, psicólogos e outros. Nesse texto, pensar a metodologia para pesquisas em educação é nosso foco, atrelado a nova escrita epistêmica de mulheres negras.

\section{Quem habita o quarto de despejo na memória?}

Trata-se de histórias narradas pelos sujeitos dessas mesmas histórias, se apropriar da escrita conferiu dignidade às memórias do passado aos dias atuais. É sobre essa escrita que nos debruçamos para problematizar aspectos que erroneamente tendem a esvaziar o sentido das muitas vozes que eclodem nas narrativas na primeira pessoa. Escritas de si, cujo papel é o 
primeiro testemunho da organização das palavras, prenhe de emoção que condensam a ideia de liberdade e exercitam o direito de se expressarem ou mesmo de valorização às escritas do punho negro, silenciadas e postergadas as reflexões permeadas dos saberes culturais. Consideramos as literaturas negras femininas diaspóricas, como análise de quem habita o "quarto de despejo", que se entenda o sentido da liminaridade ${ }^{6}$ de suas vidas no contexto da sociedade brasileira. De acordo com Victor Turner (1974), liminaridade é, portanto, “uma condição transitória na qual os sujeitos encontram-se destituídos de suas posições sociais anteriores, ocupando um entre lugar indefinido no qual não é possível categorizá-los plenamente".

De fato, ao reconhecer as inúmeras possibilidades de acolhimento às narrativas epistêmicas a partir das histórias de vida, ainda corremos o risco de a análise colonialista entrincheirar o texto, esgotando-o de tal maneira, que o objetivo principal se esmaece pela desconfiança ao não se reconhecer que nas entrelinhas de cada parágrafo, as palavras e sentidos constituem reclames, denúncias e estratégias de sobrevivência marcadas pelo silêncio, pela negação. O processo da escrita compulsiva, num movimento de desconstrução do pensamento colonialista e de valorização das histórias femininas negras na diáspora, ameniza o trauma das experiências de vida marcadas pelas mazelas impostas todos os dias, pela opressão e pela falta de oportunidades. Muitas histórias podem ser contadas a partir dos documentos sobre a escravidão ${ }^{7}$, porém, não podemos desprezar a força contida nas literaturas mais recentes, onde há projeção de lembranças que sobrevivem dentro das novas estruturas sociais, ancoradas na memória coletiva negra, principalmente em espaços culturais com referência em matrizes culturais africanas entrelaçadas com outras culturas também segregadas.

Evaristo (2007) conceitua a "escrevivência" como uma escrita comprometida com experiências vividas, buscando trazer para o centro do discurso as vivências da população negra e, principalmente, das mulheres negras, que sempre foram relegadas à margem das narrativas canônicas. A escrita feminina negra assume, portanto, outra dinâmica: parte dos desejos das próprias escritoras, das condições experimentadas por elas, ressoa suas experiências de vida. Desse modo, falar de si implica evocar lembranças, "acumular histórias que habitavam em sua casa" e nos arredores (EVARISTO, 2007, p.19).

Nessa perspectiva de uma escrita marcada pela escrevivência, Carolina Maria de Jesus, em 1960, publica o seu primeiro livro - Quarto de despejo ${ }^{8}$ - o qual retrata a sua vida de mulher negra favelada, catadora de lixo. A narrativa de Carolina nasce de suas experiências particulares, de sua subjetividade, de sua condição de mulher negra e pobre. Todavia, essa

\footnotetext{
${ }^{6}$ TURNER, Victor. O processo ritual: estrutura e anti - estrutura,Petrópolis:Vozes, 1974.

${ }^{7}$ Sobre escravidão da mulher negra, consultar SOARES, Mulher Negra na Bahia no Século XIX, 2016.

8 JESUS, Carolina Maria de. Quarto de Despejo. 8 ed. São Paulo: Ática, 2000.
} 
escrita ressoa também o lugar que a autora ocupa, a condição social experimentada por Carolina. Nesse ponto, a memória constitui papel fundamental, pois, uma vez que as narrativas têm o poder de deslocamento e encontro de realidades, partir de observações da vida, narrar com base em suas vivências e lembranças possibilita alcançar outras experiências cotidianas semelhantes.

Ao narrar a sua forma de pensar o mundo, a sua história particular, Carolina também reflete a condição de classes populares tantas vezes marginalizadas, sem assistência dos políticos e das autoridades. Sua escrita é subjetiva, mas também é de denúncia, é um grito por libertação. Ainda que a autora esteja aprisionada a uma situação de pobreza extrema, a condições subalternas de existência enquanto mulher negra e moradora da favela, ela não permite que sua palavra seja escravizada. De acordo com Fonseca e Souza (2006),

O certo é que a obra de Carolina não é fruto de uma refinada elaboração estética. Pode-se dizer que é a 'literatura em estado bruto', resultado contundente da ação de viver. É a experiência da vida transformada em mensagem literária. (p.146).

Carolina vive através da escrita. Sua voz é testemunho de um passado ainda tão presente na sociedade brasileira: o local marginal destinado a mulheres negras mães e pobres nesse país. Porém, sua narrativa também opera mudanças, reconstrói, abre espaço para que outras mulheres que vivenciam as mesmas situações possam se colocar na literatura e em todas as áreas do conhecimento. Desse modo, ainda que haja atravessamentos e empecilhos para o subalterno não falar, ele se faz ouvir, e sua fala é potente, atravessando o tempo". Assim, "a escrita afro recorrerá à memória para dela extrair a força da identidade ancestral a protagonizar as lutas do presente, que se alimenta do passado para recriá-lo, reescrevê-lo, processá-lo como elemento de luta" (FIGUEIREDO, 2009, p.66).

A rememoração atua como um mecanismo que permite às mulheres negras reelaborar a história segundo suas próprias concepções, aspirações e sentimentos. O passado representa, então, uma fonte de resistência, o impulso para lutar por transformações, para transgredir um contexto histórico marcado pela exploração e apagamento das mulheres descendentes de africanas. Dessa forma, "memória e identidade se cruzam enquanto ressignificações do passado para afirmação do presente em um processo de reavaliações, autoanálise e auto reconhecimento" (SOUZA, 2018, p.165).

\footnotetext{
${ }^{9}$ Ler SPIVAK, Gayatri Chakravorty. Pode o subalterno falar? - tradução de Sandra Regina Goulart Almeida, Marcos Pereira Feitosa, André Pereira Feitosa. - Belo Horizonte: Editora UFMG, 2010.
} 
Nessa perspectiva, Candau (2019) discorre sobre como o fluxo do tempo "ameaça os indivíduos e os grupos em suas existências" (p.15), sendo a memória um meio de tornar o passado acessível, pois através das lembranças é possível recriar o que passou e ressignificar essas vivências, enfrentando a vida presente. Conforme afirma Bosi (1994): "lembrar não é reviver, mas refazer, reconstruir, repensar, com imagens e ideias de hoje, experiências do passado" (p.54). Dessa maneira, restou às mulheres negras mergulhar no exercício da memória para reatualizar o passado, para transformar uma realidade histórica de invisibilidade, integrando ao cotidiano as suas experiências existenciais.

As narrativas pessoais de mulheres negras como Conceição Evaristo e Carolina Maria de Jesus são, portanto, fundamentais para compreender o dia a dia, as lutas e o silenciamento imposto às mulheres negras de modo geral. Assim, as histórias dessas mulheres evidenciam lembranças coletivas que permitem reflexões, que narram modos de vida. Dessa forma, as escritas pessoais de mulheres negras partem de suas individualidades, entretanto acabam por adquirir um valor coletivo, já que se escreve, de acordo com Nascimento (2018), “de um devir minoritário sobre a própria minoria" (p.420). Nessa mesma direção, Candau (2019, p.109) explicita que a escrita, como "auxiliar de uma memória forte, pode, ao mesmo tempo, reforçar o sentimento de pertencimento a um grupo, a uma cultura $[. .$.$] " e, nessa dinâmica, o escritor$ detém o poder de registrar fatos passados possibilitando a outrem se reapropriar desse passado por meio do que foi transcrito.

Nesse contexto, a memória negra feminina, mais do que resgatar a lembrança de um passado marcado pela escravidão, busca recompor as experiências no presente, revelando as lutas frente à invisibilidade e os conhecimentos da comunidade que permanecem vivos. Além disso, as memórias compartilhadas pelas mulheres negras evocam sentimentos que foram obscurecidos, encobertos e distorcidos pelos discursos oficiais e registros históricos. A partir do recurso à memória, torna-se possível resgatar esses saberes e impedir que eles se alojem no esquecimento, que se percam definitivamente. Barreto (2018, p. 37), refletindo a respeito de como "as marcas históricas comuns singularizam a experiência negra", explicita que a partir dessas singularidades históricas, "pessoas negras construíram em todo o continente culturas ricas e diversas, com elementos ressignificados e reconstruídos a partir do que vivenciaram".

A memória assume, então, uma função pedagógica: lembrar as tradições, os modos de vida, os conhecimentos produzidos pelas minorias sociais, principalmente pelas mulheres negras, uma vez que elas constituem um grupo ainda mais vulnerável, que teve, historicamente, seus direitos limados. Segundo Delgado (2007), através das narrativas 
[...] constrói-se a memória de um tempo que antecedeu ao da vida de uma pessoa. Ultrapassa-se o tempo presente, e o homem mergulha no seu passado ancestral. Nessa dinâmica, memórias individuais e memórias coletivas encontram-se, fundem-se e se constituem como possíveis fontes para a produção do conhecimento histórico (p.41).

\section{Memória diaspórica feminina como metodologia em educação}

As possibilidades interpretativas teóricas sobre a memória negra como metodologia para pesquisa encontram recepção em Geertz (1978) ao formular que "a cultura é uma teia de significados", compreendendo desta maneira, as mulheres negras particularmente na sociedade brasileira desenvolveram práticas e estratégias de sobrevivências e preservação da memória com referenciais às culturas africanas afro diapóricas. Barreto (2018), a partir de reflexões baseadas no diálogo com o Sociólogo Carlos Alberto Moreira e de argumentos explicitados por Beatriz Nascimento, discute sobre a conotação ideológica que adquire o termo quilombo na atualidade, enfatizando que este não se configura como "um território externo a ser alcançado, como no período da escravidão", mas, de acordo com a autora, "[...] como uma episteme negra, elaborada a partir do acúmulo de experimentações passadas que construíram um repertório de resistência, tradições, valores sociais, culturais e políticos”. (BARRETO, 2018, p. 37)

Sob esse viés, por meio de experiências filtradas pela memória, as mulheres negras reinterpretam as tradições, marcam os espaços de suas narrativas e desvelam realidades. Desse modo, elas encorajam outras mulheres negras a romperem o ciclo do silenciamento dando veemência a suas vozes e não permitindo que suas narrativas partam dos comandos da Casa Grande, mas sim de seus próprios olhares, pois as histórias de vida narradas pelas mulheres negras não são "para ninar os da Casa Grande, mas para incomodá-los em seus sonos injustos" (EVARISTO, 2007, p.21). Segundo Streck, (2006, p.108): “Trata-se da insurgência no sentido de recuperar ou criar a possibilidade de dizer a sua palavra, de fazer com que a revolta e a indignação contra as condições opressivas se transformem numa força potencializadora de mudanças".

As narrativas acadêmicas discriminaram e postergaram as questões ideológicas, que determinaram as referências sobre a existência das mulheres negras em diferentes lugares. $\mathrm{Na}$ contemporaneidade, pouco a pouco se delineou um movimento de reação política e reflexiva sobre a invisibilidade das experiências de mulheres negras em diferentes momentos da história. No bojo dessas investidas, sempre positivas no sentido de valorização até mesmo das trajetórias com sofrimentos, o sentimento que surge é de identificação representativa relacionada aos grupos marginalizados que também sofrem com a exclusão, o racismo e ausência de oportunidades sociais. A escrita de si liberta, e ao não permitir que a palavra fosse escravizada, 
subalternizada, a exemplo da literatura de Carolina de Jesus, as mulheres negras escritoras propõem uma revolução teórica com abordagens realistas que descrevem o cotidiano entremeado pelas questões inerentes à raça, ao gênero e posição social.

De acordo com Santana (2020), a escrita da mulher negra, além de externar suas experiências e percepções sobre a vida, também representa uma forma de "desabafo", de se livrar dos gritos presos na garganta, dos traumas vivenciados e, desse modo, percorrer caminhos que conduzam à emancipação. A autora defende que "a memória trabalhada na escrita de si é uma possibilidade de inventar uma nova interioridade, rompendo com a subordinação e a subalternização [...]". Segundo Santana (2020), a oportunidade de criar futuros está justamente no exercício de se apropriar, narrar e difundir as "histórias escondidas" (SANTANA, 2020, p. 204).

A questão que trazemos à tona é a utilização desse material da escrita do próprio punho de mulheres negras, com base em suas memórias e vivências em diferentes campos do conhecimento, como metodologia para análise dos sujeitos, ou mesmo como técnica/instrumento de pesquisa para fazer emergir as histórias negligenciadas pelo academicismo. Embora sejam inúmeras as possibilidades de análise para a pesquisa em Educação, com o uso da oralidade e memória escrita, sugerimos alguns caminhos metodológicos para arguição das informações. Por exemplo, a pesquisa qualitativa compreensiva proposta por Crusoé (2014) e Amado: Crusoé (2017), com base na análise de conteúdo de Bardin (2017; 2011), cuja técnica consiste em "um processo que visa desvendar o sentido do discurso, despedaçando-fragmentando o seu conteúdo em temas, proposições ou acontecimentos, de modo a nos permitir a descoberta de outros sentidos" (CRUSOÉ, 2014, p. 60). Quando na centralidade da pesquisa estão testemunhos e experiências vivenciadas por mulheres negras, inseridas em diversos lugares sociais, suas narrativas escritas e orais irão contribuir para o conhecimento do pensamento e posturas frente a determinadas situações relacionadas à educação, perpassado por aspectos que irão singularizar suas histórias, como formação acadêmica, geração, região, identidade cultural, militância política, religião, cor e sexualidade.

A pesquisa qualitativa compreensiva vem sendo utilizada nas pesquisas no grupo de pesquisa GEPPCE (Grupo de Estudo e Pesquisa em Práticas Curriculares e Educativas) do Programa de Pós-Graduação em Educação na Universidade do Sudoeste da Bahia, possibilitando a análise sistemática dos dados coletados, particularmente em entrevistas, sobre a prática educativa de professores e as questões relativas às identidades pessoais que reverberam no trabalho em sala de aula. A técnica de se esmiuçar as informações, através da abordagem 
qualitativa compreensiva, onde as palavras têm sentidos e significados a serem discutidos com o intuito de revelar concepções e atitudes sobre temas relacionados à prática docente, vem atendendo as perspectivas de produção de conhecimento baseado nas informações coletas no campo e com sujeitos diretamente envolvidos no processo de educação. A técnica de uma análise nas entrelinhas das informações não é uma ação interpretativa nova para as Ciências Humanas, contudo, vem revelando-se bastante promissora no campo da educação, como fonte privilegiada, ao possibilitar aos pesquisadores e pesquisados a reflexão sobre narrativas pessoais e trajetórias educacionais. Atente-se para o fato de que as narrativas diaspóricas femininas negras adentram a academia, e a área de Educação orienta para percepção dos testemunhos que desconstroem a hegemonia do conhecimento ao tornarem mulheres negras protagonistas de suas próprias histórias.

Os estudos decoloniais ${ }^{10}$ discutem como a colônia é uma forma de poder e como cada país tem a necessidade de realizar uma descolonização, que se refere não apenas à independência política, mas a um processo de reelaboração interna das práticas culturais, que tornem possível a construção de outras formas do sujeito, promovendo o reconhecimento da diferença cultural.

É preciso reafirmar que as epistemologias decoloniais constituem metodologias que pressionam de fora para dentro do eixo universitário, o delinear de outras abordagens sem necessariamente propor o banimento dos estudos conhecidos. Compartilhar ideias e perspectivas robustece as análises, possibilita interlocução e renovação do pensamento, desprende abordagens engessadas nas premissas ocidentalizantes.

A memória celebra acontecimentos do passado, mas não necessariamente do passado muito longínquo. Decorrido os séculos da escravidão, permanecem os estigmas sociais, e com ênfase o cotidiano das mulheres negras afro diaspóricas carregam o fardo dos lugares no contexto da casa grande e senzala. Assim, colocar em foco os relatos pessoais de mulheres negras é trazer para o centro do discurso experiências de um coletivo que foi mantido à margem como "massa categorizada, estigmatizada e incipiente" (CLARK, 2019, p.84).

Segundo Clark (2019), as narrativas de cada pessoa negra refletem "a exigência de todos os pretos por uma identidade positiva, o reconhecimento e o respeito por sua individualidade, a reinvindicação de sua humanidade total" (p.84). Essas narrativas, conforme evidenciado pelo autor, quando analisadas além da superfície, permitem compreender que o desejo dos homens

\footnotetext{
${ }^{10}$ A colonialidade "pode ser compreendida como uma lógica global de desumanização que é capaz de existir até mesmo na ausência de colônias formais". Já a decolonialidade "refere-se à luta contra a lógica da colonialidade e seus efeitos materiais, epistêmicos e simbólicos” (MALDONADO-TORRES; 2018, p.40).
} 
negros e mulheres negras é o de serem respeitados em suas individualidades, de romperem com os "padrões de acomodação" e de lutarem contra o racismo e as injustiças que marcam suas vidas e as de tantos outros. Nesse contexto, as mulheres negras, a partir de seus relatos pessoais, constroem interpretações de si e maneiras de pensar suas presenças, seus adoecimentos, suas dores e superações.

\section{Conclusão}

De fato, não houve por parte das autoras a pretensão de esgotar a discussão deste tema. Trata-se de uma abordagem preliminar sobre a importância da utilização das narrativas epistêmicas femininas negras como fonte para pesquisa em educação. Essas narrativas orais e literatura direcionam nossos olhares para o protagonismo de mulheres e suas escritas sobre si e sobre as outras, para compreensão do cotidiano e dos silêncios impostos a mulheres negras. Um desses aspectos é a ausência de documentos sobre depoimentos de primeira mão das mulheres negras no contexto da escravidão. A produção feminina preenche a lacuna com exemplos de escritas pessoais, desse modo, a memória se faz instrumento e maná para as mulheres negras, que se encontram e se reconhecem através das narrativas de suas realidades vivenciais. Esse encontro, carregado de afeto e de dor, traz sofrimento, mas também faz emergir a força da mulher negra que supera o apagamento histórico, as desigualdades raciais e de gênero, os desafios do dia a dia.

As histórias das mulheres negras visam não apenas lembrar o passado, mais do que isso, buscam recuperar as suas experiências para delas evocar os sentimentos solapados, invisibilizados, onde o conhecimento hegemônico e totalizante corroborou a distorção das vivências negras. A memória feminina afro diapórica, inevitavelmente, descontrói perspectivas, nos abala, desafia e se contrapõe ao conhecimento com pretensão de hegemonia, ressignificando as interpretações e problematizando situações inequivocadamente naturalizadas pela exclusão das mulheres ou por sua participação diferenciada na sociedade.

Ao adentrarem, ainda que com certa reserva de alguns estudiosos, o ambiente acadêmico, as narrativas epistêmicas femininas constituem fonte importante para pesquisa em educação. Discutir sobre a memória, por meio das lembranças de mulheres negras relacionadas aos processos de educação, faz-se necessário e merecedor de reflexões sobre as ideologias que perpassam suas vivências no contexto da sociedade brasileira e na contemporaneidade dos acontecimentos. É necessário, ainda, enfatizar que a literatura epistêmica feminina negra pode dialogar com a produção acadêmica, no sentido de robustecer as interpretações sobre as vivências de mulheres negras inseridas no campo da educação. 


\section{REFERÊNCIAS}

AMADO: FERREIRA. Janaína; Marieta de Moraes. Usos e abusos da História Oral. Rio de janeiro, Editora Fundação Getúlio Vargas, 1996.

BARDIN, L. L’Analyse de contenu. Editora: Presses Universitaires de France, 1977.

Análise de conteúdo. SP: Edições 70, 2011.

BARRETO, Raquel. Beatriz Nascimento, uma breve apresentação. In: NASCIMENTO, Maria Beatriz. Beatriz Nascimento, quilombola e intelectual: possibilidades nos dias de destruição. Diáspora africana: Editora Filhos da África, 2018.

BOSI, E. Memória e sociedade: lembranças de velhos. 3. ed. São Paulo: Companhia das Letras, 1994.

CANDAU, Joël. Memória e identidade. Tradução de Maria Leticia Ferreira. - 1. ed. São Paulo: Contexto, 2019.

CLARK, Kenneth Bancroft. O protesto preto: James Baldwin, Malcolm X e Martin Luther King. Diáspora Africana: Editora Filhos da África, 2019.

DELGADO, Lucilia de Almeida Neves. História oral - Memória, tempo, identidades. Autêntica Editora, 2007.

EVARISTO, Conceição. Da grafia-desenho de minha mãe um dos lugares de nascimento da minha escrita. In: ALEXANDRE, Marcos Antônio (org.). Representações performáticas brasileiras: teorias, práticas e suas interfaces. Belo Horizonte: Mazza Edições, 2007.

Olhos D’água. Rio de Janeiro: Pallas: Fundação Biblioteca Nacional, 2016.

FIGUEIREDO, Fernanda Rodrigues de. A mulher negra nos cadernos negros: autoria e representações. Dissertação. (Programa de Pós-Graduação em Letras) - Faculdade de Letras, Universidade Federal de Minas Gerais. Belo Horizonte - MG, 2009.

FONSECA, Maria Nazareth Soares; SOUZA, Florentina da Silva (Orgs.). Literatura Afrobrasileira. Salvador: CEAO, 2006.

JESUS, Carolina Maria de. Quarto de Despejo. 8 ed. São Paulo: Ática, 2000.

MALDONADO-TORRES, Nelson. Analítica da colonialidade e decolonialidade: algumas dimensões básicas. In: BERNARDINO-COSTA, Joaze; MALDONADO-TORRES, Nelson; GROSFOGUEL, Ramón. (Org.). Decolonialidade e pensamento afrodiaspórico. Belo Horizonte: Autêntica Editora, 2018. 
MOREIRA, Núbia Regina. O feminismo negro brasileiro: um estudo do movimento de mulheres negras no Rio de Janeiro e São Paulo. Dissertação (Mestrado) - Universidade Estadual de Campinas, Instituto de Filosofia e Ciências Humanas, Campinas, SP, 2007. OLIVEIRA, Maria Marly de. Como se faz pesquisa qualitativa. $7^{\text {a }}$ ed. Rio de Janeiro, Editora Vozes, 2016.

PASSERON,J.C. A encenação e o corpus: biografias, fluxos, itinerários, trajetórias. In: .O raciocínio sociológico: o espaço não- popperiano do raciocínio natural. Petrópolis: Vozes, 1995.

SANTANA, Bianca. A escrita de si de mulheres negras: memória e resistência ao racismo. Tese (Doutorado) - Escola de Comunicações e Artes da Universidade de São Paulo, São Paulo, 2020.

SANTOS, Edimilson Menezes. Observações introdutórias ao nexo entre método e conhecimento em Descartes. In: AMADO, João; CRUSOÉ, Nilma Margarida de Castro (Org.). Referenciais Teóricos e metodológicos em Educação e Ciências Sociais. Vitória da Conquista :Edições UESB,2017, pp.21-37.

SOARES, Cecilia C. Moreira. Mulher Negra na Bahia no Século XIX. Eduneb/Fundação Palmares, 2006.

. "Encontros, Desencontros e (Re) Encontros da Identidade de Matriz Africana: A História de Cecilia do Bonocô Onã Sabagi. Tese de doutorado em antropologia em Antropologia, defendida na Universidade Federal de Pernambuco, 2009.

SOUZA: CRUZ. Elizeu Clementino de; Núbia da Silva. Pesquisa (auto)biográfica: sentidos e implicações para o campo educacional In: AMADO, João; CRUSOÉ, Nilma Margarida de Castro (Org.). Referenciais Teóricos e metodológicos em Educação e Ciências Sociais. Vitória da Conquista: Edições UESB,2017, pp.167194.

SOUZA, Grace Kelly Silva Sobral. Mulheres negras: memórias da trajetória de luta e resistência dos movimentos de mulheres negras do Maranhão a partir do "Grupo de Mulheres Negras Mãe Andresa”. Kwanissa, São Luís, v.1, n.1, p.154-172, jan./jun. 2018.

SPIVAK, Gayatri Chakravorty. Pode o subalterno falar? - tradução de Sandra Regina Goulart Almeida, Marcos Pereira Feitosa, André Pereira Feitosa. - Belo Horizonte: Editora UFMG, 2010.

STRECK, D. R. 2006b. Práticas educativas e movimentos sociais na América Latina: aprender nas fronteiras. Série Estudos: Periódico do Mestrado em Educação da UCB, 22, 99112.

TURNER,W.Victor. O processo ritual: estrutura e anti - estrutura, Petrópolis:Vozes, 1974. 


\section{SOBRE AS AUTORAS:}

\section{Cecilia Conceição Moreira Soares}

Docente Titular na Universidade do Estado da Bahia - UNEB/ Departamento de EducaçãoCampus I. Docente Colaboradora Programa de Pós Graduação em Educação / Universidade Estadual do Sudoeste da Bahia - UESB. Linha II: Currículo, Práticas Educativas e Diferença. E-mail: ceciliasoares@yahoo.com.br

(iD https://orcid.org/0000-0003-1803-6370

\section{Grácia Lorena da Silva Jorge}

Docente no Instituto Federal do Norte de Minas Gerais - IFNMG / Campus Araçuaí. Mestranda em Educação pela Universidade Estadual do Sudoeste da Bahia - UESB. Linha II: Currículo, Práticas Educativas e Diferença. E-mail: gracia.jorge@ifnmg.edu.br

iD https://orcid.org/0000-0003-0071-1569 